\title{
Clinical Characteristics of Aggressive Behavior Problems in Children with Autism Spectrum Disorder: Preliminary Study
}

\author{
Young-Hui Yang ${ }^{1,2}$, Hyen-Jung $\mathrm{Kim}^{2}$, and Won-Hye Lee $^{3}$ \\ ${ }^{1}$ Department of Child and Adolescent Psychiatry, National Center for Mental Health, Seoul, Korea \\ ${ }^{2}$ Center for Behavior Development, National Center for Mental Health, Seoul, Korea \\ ${ }^{3}$ Department of Clinical Psychology, National Center for Mental Health, Seoul, Korea
}

\section{공격적 문제행동을 보이는 자폐스펙트럼장애 아동청소년의 임상적 특징: 예비연구}

\author{
양영희 ${ }^{1,2}$, 김현정 ${ }^{2}$, 이원혜 ${ }^{3}$ \\ 국립정신건강센터 소아청소년정신과, ${ }^{1}$ 국립정신건강센터 행동발달증진센터, ${ }^{2}$ 국립정신건강센터 심리건강과 ${ }^{3}$
}

\begin{abstract}
Objectives: The aim of this study was to investigate the clinical characteristics of aggressive behavior problems in children and adolescents with autism spectrum disorder (ASD).

Methods: Children and adolescents with ASD, aged 6-18 years, were included in this study. We divided them into two groups according to the presence or absence of aggressive behavior. They were assessed using three scales, the Korean-Child Behavior Checklist (K-CBCL), Behavior Problem Inventory, and Social Communication Questionnaire, which were completed by their parents, who conducted a continuous performance test to evaluate their attention function. The statistical analysis was done using the Mann-Whitney U-test between the two groups at a p-value of 0.05 .

Results: A total of 17 children participated in this study. Ten children ( 7 boys, $12.4 \pm 4.27$ years) were included in the group with aggressive behavior problems and 7 children ( 6 boys, $13.8 \pm 3.53$ years) in the group without aggressive behavior problems. There were no significant differences in the age, gender or intelligence quotient of the two groups. The children with aggressive behavior problems showed a trend of higher T-scores in the attention problems and anxiety/depressed subscale of the CBLC ( $<<0.1)$.

Conclusion: The results suggest that aggressive behavior problems in children with ASD may be related to their attention problems, anxiety and depression.
\end{abstract}

Key Words: Aggression; Autism spectrum disorder; Attention.

Received: May 16, 2017 / Revision: June 30, 2017 / Accepted: July 6, 2017

Address for correspondence: Young-Hui Yang, Department of Child and Adolescent Psychiatry, National Center for Mental Health, 127 Yongmasan-ro, Gwangjin-gu, Seoul 04933, Korea

Tel: +82-31-725-6081, Fax: +82-2-2204-0394, E-mail: yhyang12@korea.kr

\section{서 론}

자폐스펙트럼장애(autism spectrum disorder, ASD)는 일 생의 초기에 진단되는 신경발달장애(neurodevelopmental disorder)로 타인과의 상호작용의 어려움과 반복적이거나 제한된 행동과 흥미를 특징으로 한다. ${ }^{1)}$ 자폐스펙트럼장애의 공존질환 중 일부는 $\mathrm{ASD}$ 의 주요 특징과 구별이 어려울 뿐만 아니라 의 사소통의 제한으로 인해서 진단이 어려울 수 있다. 일례로 자폐

This is an Open Access article distributed under the terms of the Creative Commons Attribution Non-Commercial License (http://creativecommons.org/licenses/by-nc/4.0) which permits unrestricted non-commercial use, distribution, and reproduction in any medium, provided the original work is properly cited.
스펙트럼장애에서 보이는 반복적인 행동과 흥미는 강박장애나 틱장애와 감별하기 어려울 수 있다. 공존질환은 다양해서 우울 증이나 불안장애와 같은 정서장애에서부터 주의력결핍 과잉행 동장애(attention-deficit hyperactivity disorder, ADHD) 그 리고 정신증까지 보일 수 있으며 공격적인 행동이나 자해 등의 행동문제가 나타나기도 한다. ${ }^{23}$

자폐스펙트럼장애 아동에서 문제 행동(problem behavior)에 대한 범위나 정의는 다양할 수 있지만 대체로 자해나 타해와 같은 공격적인 행동, 심각할 정도로 지시에 따르지 않거나 반복 하는 행동 등으로 볼 수 있다. 이 중에서도 공격적인 행동은 매우 심각한 문제로 본인의 일상생활을 어렵게 할 뿐만 아니라 
$\mathrm{ASD}$ 아동을 돌보는 가족과 교사를 비롯한 타인에게 많은 고 통을 주므로 적절한 평가와 개입이 필요하다. 자폐스펙트럼장 애에서 공격적인 문제행동의 유병률은 비교적 넓은 범위로 보 고되고 있는데, 청소년을 포함한 일부 연구들을 보면 $19 \%{ }^{4}$ 에 서 $68 \% \%^{5}$ 에까지 이른다. 이러한 결과는 연구 대상의 특징, 연령, 공격성의 범위나 정의, 측정도구 등에 인한 것으로, 한 연구에 따르면 보호자를 향한 공격성은 자폐스펙트럼장애 아동 전체 의 $68 \%$ 인 반면에 보호자가 아닌 타인을 대상으로 한 공격성을 보인 경우는 $49 \%$ 로 차이가 있음을 보고하였다. ${ }^{5)}$ 이러한 평가 또는 측정방법들의 차이를 감안하더라도 $\mathrm{ASD}$ 에서 상당한 비 율로 공격적인 문제행동이 보고되고 있음을 알 수 있다.

공격적인 행동의 특징과 양상, 더 나아가 관련 요인에 대해서 조사한 연구들을 살펴보면 지능과 언어발달과 같은 기능, 자 폐스펙트럼장애의 주요 증상, 동반된 공존질환 등이 관련성 이 있는 것으로 보고되고 있다. 구체적으로 보면 낮은 비언어 성 지능, 부족한 의사소통기술, 사회적 상호작용의 어려움, 심 각한 상동행동 등과 관련이 있다는 보고난 낮은 지능이 관련 이 있다는 연구결과 ${ }^{78}$ 와 같이 인지기능의 저하나 자폐스펙트 럼장애의 주요 증상과 공격성이 관련됨이 보고되었다. 반면에 다른 연구에서는 낮은 지능이나 언어 기능의 저하가 타인에 대 한 공격이나 자해 등의 공격적인 행동과 관련이 없으며 자폐증 의 심각도가 주요한 위험요인일 가능성이 제시되었고, ${ }^{9}$ 또 다 른 연구에서는 공격성이 자폐증상의 심각도나 지능과는 관련 이 없었다.58) 이러한 일치되지 않는 연구 결과들은 $\mathrm{ASD}$ 에 대 한 진단, 연구 대상, 관심이 되는 요인에 대한 측정 방법뿐만 아 니라 $\mathrm{ASD}$ 의 공격성에 대한 기준이나 평가방법에 따른 차이에 기인한다고 할 수 있겠다. 실제로 $\mathrm{ASD}$ 를 비롯한 발달장애의 공격성을 평가하는 방법은 부모나 교사의 보고 또는 임상가의 평가에 의해서 이루어지며 한 연구에서는 이와 관련된 평가도 구를 15 개로 보고하였다. ${ }^{10}$ 공격적인 행동의 특징을 세분화하 여 시행한 연구에서는 언어폭력이나 괴롭힘과 같은 폭력성은 높은 지능과 관련이 있는 반면에 신체적인 폭력은 낮은 지능 이나 의사소통의 어려움과 관련이 있다고 보고되었다. ${ }^{4}$

이외에도 스트레스와 같은 환경요인과의 관련이 있거나,11) 공격성에 대한 대처방안으로 수면 문제, 내재화 문제, 그리고 주의집중력 문제에 대한 해결이 제안되기도 하였다. ${ }^{8)}$ 뇌파의 이상과 공격성과의 관련성을 제시한 연구 ${ }^{2)}$ 는 신경학적인 이상 이 원인 요인일 가능성을 보여준다. 최근에는 Neurologin-3 유전자의 mutation이 $\mathrm{ASD}$ 에서 보이는 공격성과 관련이 있으 며, 이 증상이 리스페리돈(risperidone) 약물치료로 호전되었다 는 동물실험연구 ${ }^{13}$ 가 있었다. 또한 최근에 발표된 $\mathrm{ASD}$ 동물 모 델을 대상으로 한 연구에서 바소프레신(vasopressin)과 옥시토 신(oxytocin)이 공격성을 줄였다는 결과보고 ${ }^{14)}$ 는 $\mathrm{ASD}$ 의 공격
성에 대한 약물치료로 리스페리돈과 아리피프라졸(aripiprazole) 이외 새로운 가능성을 보여주었다.

공격적인 문제행동의 약물치료에 대한 연구들 ${ }^{15-17)}$ 은 이전 부터 있어왔다. 이 연구들은 자폐스펙트럼장애에서 약물치료 의 근거를 제공하였으나 이자극성을 다양하게 세분화하지 않 고 쉽게 짜증을 내는 것에서부터 타인에 대한 심각한 공격성과 자해까지 포함하였다. ${ }^{17}$ 공격적인 행동문제에 대한 약물치료로 항정신병약물(antipsychotics), 항전간제(antiepileptic drug), 리튬(lithium) 등이 있으나 효과가 제한적이며 이외에 행동치 료 및 의사소통기능 향상을 위한 정신사회치료가 제시되고 있 다. ${ }^{18)}$ 현재 공격성에 대한 약물적, 비약물적 치료가 제시되고 있으나 이들이 치료효과가 충분하지 않다. 문제행동 또는 문 제행동을 보이는 $\mathrm{ASD}$ 아동에 대한 특징 연구를 통해 그에 따 른 개입을 적용하는 것이 공격적인 문제행동을 줄이는데 기여 할 것으로 보인다.

본 연구는 공격적인 문제행동을 보이는 자폐스펙트럼장애 아동의 특징에 대해서 알아보고자 하였다. 이를 위해서 자폐스 펙트럼장애 아동청소년 중에서 공격적인 문제행동을 보이는 아동청소년과 공격적 문제행동을 보이지 않는 아동청소년의 두 집단으로 나누어 임상적 특징을 비교하였다.

\section{방 법}

\section{연구참여 대상자}

본 연구는 서울 시내의 한 병원에 내원한 아동청소년 중 본 연구에 대해서 설명을 듣고 연구 참여에 동의한 6 세 이상 18 세 이하의 아동청소년 중 자폐스펙트럼장애로 진단받은 아동청 소년과 그 보호자를 대상으로 하였다. 자폐스펙트럼장애 진 단은 미국 정신의학회에서 발간한 정신질환의 진단 및 통계편 람 제 5판(Diagnostic and Statistical Manual of Mental Disorders -5$)^{11}$ 에 근거하여 소아청소년정신건강의학과 전문의에 의해서 이루어졌다. 두 집단 간 비교를 위해 최근 6개월 이상의 기간 동안 일상생활에 어려움을 보일 정도로 공격적 문제행동 을 보인 아동청소년과 이러한 공격적 문제행동이 없었던 아동 청소년으로 나누어 모집하였다. 공격적 문제행동은 자신과 타 인에게 위해를 끼치거나 끼칠 수 있는 행동으로 보호자의 보 고와 임상평가 시의 관찰을 통해 확인하였다. 두 집단 모두 다 음의 기준 중 어느 하나 이상을 만족하는 경우 참여대상에서 제외하였다. 1) 중등도 이상의 내과적 또는 신경과적 질환을 가지고 있거나, 2) 정신병적 증상을 보이거나, 3) 중등도 이상 의 두부외상 과거력이 있거나, 4) 본 연구에서 시행하는 검사 참여가 어려운 경우에는 제외하였다. 본 연구는 연구가 진행된 병원의 임상시험윤리위원회(Institutional Review Board, IRB) 
승인을 받았다(IRB No. 2015-23).

\section{평가 도구 및 방법}

본 연구의 참여자는 연구에 대한 설명을 듣고 참여 동의(informed consent) 후에 설문지를 작성하고 신경심리검사를 받 았다. 설문지는 보호자가 작성하였으며, 신경심리검사는 아동 청소년을 대상으로 하였다. 공격적 행동의 여부는 보호자를 통한 병력 청취 또는 병원에 내원하여 시행한 평가와 치료 과 정에서 나타난 양상을 모두 포함하여 정하였다. 모든 설문평 가와 검사는 가능한 하루에 실시하였으나 참여자의 상황에 따 라 설문평가와 신경심리검사를 2일에 걸쳐 나누어 시행하였다.

\section{문제행동 평가(Behavior Problem Inventory, BPI)}

발달장애를 가진 개인의 자해행동, 상동행동, 공격적 행동 의 심각도와 빈도를 평가하기 위해 개발되었다. ${ }^{19}$ 전체 52 개의 항목으로 자해행동 평가항목 15 개, 상동행동 평가항목 25 개, 공격적/파괴적 행동 평가항목 12 개로 구성되어 있다. 5 단계로 평가하게 되는데 심각도는 '없음, '경도', '중도', '중고도', '고도' 중 하나로 평가하며 0 4점 사이로 평정한다. 빈도는 '없음, '매월', '매주', '매일', '매시간' 중 하나로 평가하며 이를 점수화 하여 0 4점 사이로 평정한다. 심각도와 빈도의 각 항목의 총 점은 순서대로 60점, 100점, 그리고 48점으로 총점은 208점이 다. 국내에서는 시설에 거주하는 10 55세 사이의 발달장애인 120 명을 대상으로 한 표준화 연구가 있다. ${ }^{20)}$ 이 보고에서 한국 판 적응행동검사의 문제행동 평가척도와 상관분석 시 유의한 공존 타당도를 보였다. 이 검사는 보호자에게 시행되었다.

\section{아동행동평가(Korean-Child Behavior Checklist, K-CBCL)}

Achenbach 등1)이 개발한 도구로 아동청소년기의 다양한 정서와 행동의 어려움 및 사회적 적응양상을 알아볼 수 있다. 주양육자가 작성하며, 평가결과는 문제행동총점, 내재화점수, 외현화점수로 크게 나뉘며 세부 항목으로 불안/우울, 위축/우 울, 신체증상, 사회적 미성숙문제, 사고문제, 주의집중문제, 규 칙위반, 공격행동으로 나뉜다. 본 연구에서는 각 항목의 T점수 를 기준으로 하였다.

\section{한국어판 사회적 의사소통 설문지(Korean version of Social Communication Questionnaire, K-SCQ)}

자폐증상과 관련된 폭 넓은 증상에 대해서 평가하는 도구로 자폐면접도구(Autism Diagnostic Interview-Revised, ADI-R) 에서 문항을 추출하여 만들어졌다.22) 언어가 없는 대상부터 유 창한 언어능력을 가진 성인까지 평가할 수 있다. 두 가지의 형 태가 있는데, 일생(lifetime form)과 현재(current form)를 모
두 평가할 수 있으며 각각 40문항으로 되어 있다. 보호자가 작 성하게 되어 있으며 문항은 '예/아니요'의 답변 형식으로 되어 있다. 점수가 높을수록 $\mathrm{ASD}$ 일 가능성이 높아진다. 한국어판 사회적 의사소통 설문지에 대한 타당화 연구 ${ }^{23}$ 에서 Korean version of Social Communication Questionnaire(K-SCQ, 일생) 의 Cronbach's $\alpha$ 값은 $0.95, \mathrm{~K}-\mathrm{SCQ}$ (현재)에서 0.93으로 높은 수준의 신뢰도를 나타냈다.

\section{지능평가}

본 연구에 참여한 만 6 16세 이하의 아동청소년을 대상으로 한국판 아동을 위한 웩슬러 지능평가(Korean Educational Development Institute-Wechsler Intelligence Scale for Children-IV, KEDI-WISC)를 시행하였고, 만 16세 이상인 경우에 는 한국판 성인용 웩슬러 지능검사(Korean-Wechsler Adult Intelligence Scale, K-WAIS)를 이용하여 지능을 평가하였다. 이 검사를 통해서 전체 지능지수와 소검사 결과가 산출되었다.

\section{주의집중력평가}

주의집중력을 평가하기 위하여 연속수행검사(Continuous Performance Test)인 종합주의력검사(Comprehensive Attention Test, CAT)를 시행하였다. ${ }^{24)}$ 이 검사를 통해서 단순주의력, 선택주의력, 지속주의력, 분할주의력, 작업기억력 등 5가지 종 류의 주의력을 평가할 수 있다. 다섯 개의 소검사 중 단순선택 주의력은 시각 자극 또는 청각 자극에 집중할 수 있는 능력을 평가한다. 이 검사는 오경보오류, 누락오류, 반응시간 그리고 반응시간표준편차의 4 가지 항목으로 평가하며 각각 정상(1표 준편차 이하), 경계(1 1.6표준편차), 저하(1.6표준편차 이상)로 나누어 제시된다. 본 연구에서는 6 16세 사이의 아동청소년을 대상으로 시각 자극에 대한 단순주의력 평가를 시행하였고, 경 계와 저하를 모두 '저하로 포함하여 집단 간 '정상'과 '저하'의 분포를 비교하였다.

\section{통계분석}

인구학적 특징과 임상 양상에 따른 변수는 기술적 통계분 석을 시행하였고, 공격적 문제행동을 보이는 $\mathrm{ASD}$ 군과 공격 적인 문제행동을 보이는 않는 $\mathrm{ASD}$ 군 사이의 비교에서 연속 변 수에 대해서는 Mann-Whitney U-test를 시행하였으며, 범주 형 변수에 대해서는 Fisher exact test를 시행하였다. 통계적 유 의수준은 p-value 0.05 이하로 하였다.

\section{결 과}

본 연구에 참여한 17 명 중에 공격적 문제행동을 보이는 집단 
Table 1. Demographic characteristics of participants

\begin{tabular}{lccc}
\hline & ASD w/ aggressive behavior $(\mathrm{n}=10)$ & ASD w/o aggressive behavior $(\mathrm{n}=7)$ & $\mathrm{p}$-value \\
\hline Male $(\mathrm{n}, \%)$ & $7(70.0)$ & $6(85.7)$ & $0.603^{*}$ \\
Age (year, mean \pm SD) & $12.4 \pm 4.27$ & $13.8 \pm 3.53$ & $0.270^{\dagger}$ \\
Intelligence Quotient (mean \pm SD) & $62.5 \pm 26.62$ & $59.2 \pm 8.55$ & $0.408^{\dagger}$ \\
Admission history to a psychiatric ward & $5(50)$ & 0 & $0.044^{*}$ \\
Current medication $(\mathrm{n}, \%)$ & $9(90)$ & $2(28.6)$ & $0.035^{*}$ \\
Antipsychotics & $9(90)$ & $2(28.6)$ & $1(14.3)$ \\
Antiepileptics & $3(30)$ & $1(14.3)$ & $1(14.3)$ \\
Methylphenidate, atomoxetine & $3(30)$ & $7(70)$ & \\
SSRI, benzodiazepine, benztropine & . & & \\
\hline
\end{tabular}

*Fisher exact test, two-tailed, ${ }^{\dagger}$ Mann-Whitney U-test. ASD: autism spectrum disorder, SD: standard deviation, SSRI: selective serotonin reuptake inhibitor

은 10명이었고, 7명은 공격적 문제행동을 보이지 않았다(Table 1). 공격적 문제행동을 보이는 ASD 집단은 7명(70\%)이 남아였 고, 평균나이는 12.4세(SD 4.27세)였다. 평균 지능 지수는 62.5 (SD 26.62)였고, 절반인 5명이 공격적인 행동문제로 입원한 과거력이 있었다. 공격적 문제행동이 없는 $\mathrm{ASD}$ 집단에서 6명 (85.7\%)이 남아였고, 평균 나이는 13.8세(SD 3.53세)였고, 2명 (28.6\%)이 약물을 복용하고 있었다. 평균 지능 지수는 59.2(SD 8.55)였다. 두 집단 사이의 나이, 성별 그리고 지능의 비교분석 에서 통계적으로 유의한 차이가 나타나지 않았다. 공격적 문제 행동을 보이는 $\mathrm{ASD}$ 집단은 약을 복용하고 있는 9 명 모두가 항정신병 약물을 복용하고 있었고, 이 중 8명이 1 4 mg 사이 용 량의 리스페리돈을 복용하였으며, 평균용량은 $2.1( \pm 1.53) \mathrm{mg}$ 이 었다. 이외에 기분 조절제, 메칠페니데이트(methylphednidate), 아토목세틴(atomoxetine), 항우울제, 항불안제, 벤즈트로핀 (benztropine) 등의 약물을 추가로 복용하고 있었다. 반면에 공격적 문제행동을 보이지 않는 $\mathrm{ASD}$ 집단은 2 명이 약물을 복 용하고 있었는데 2 명 모두 리스페리돈을 복용하고 있었고, 용 량은 각각 $3,1 \mathrm{mg}$ 이었다. 이외에 기분 조절제, 아토목세틴 등 의 약물을 복용하였다.

\section{임상 평가 결과(Table 2)}

문제행동 평가(Behavior Problem Inventory, BPI) 결과 두 집단 사이에서 공격적 문제행동의 빈도와 심각도 점수는 통 계적으로 유의한 차이를 보였으나, 자해행동과 상동행동의 심 각도와 빈도는 두 집단 사이에 통계적으로 유의한 차이를 보 이지 않았다. 자해행동은 공격적 문제행동을 보이는 ASD 집 단에서 빈도와 심각도가 좀 더 높은 경향을 보였다 $(\mathrm{p}<0.1)$. 전 체 문제행동의 빈도도 공격적 문제행동을 보이는 $\mathrm{ASD}$ 집단에 서 좀 더 많았다 $(\mathrm{p}=0.038)$. 공격적 문제행동의 양상은 사물을 부수거나, 타인의 옷을 찢거나, 타인을 때리거나 발로 차고, 밀 치고, 깨물고, 할퀴는 행동이 있고, 폭언을 하거나 타인을 괴롭 히는 행동 등이 있었다. 한 가지 양상의 공격적인 행동만을 보
이거나 여러 가지의 공격적 행동을 같이 보이기도 하였다. 아동행동평가(Korean-Child Behavior Checklist, K-CBCL) 결과 총행동문제와 외현화문제, 사회적 미성숙문제, 비행문 제, 그리고 공격적문제의 $\mathrm{T}$ 점수가 공격적인 문제행동을 보이 는 $\mathrm{ASD}$ 집단에서 통계적으로 유의하게 높은 것으로 나타났다 $(\mathrm{p}<0.05)$. 또한 불안/우울 $(\mathrm{p}=0.071)$ 과 사고문제 $(\mathrm{p}=0.055)$, 주의 집중문제 $(\mathrm{p}=0.055)$ 가 공격적인 문제행동을 보이는 $\mathrm{ASD}$ 집단 에서 높은 경향을 보였다. 사회적 의사소통 설문지 $(\mathrm{K}-\mathrm{SCQ})$ 의 결과분석에서 두 집단 간 통계적으로 유의한 차이를 보이는 영역은 없었다.

\section{주의집중력 검사 결과(Table 3)}

시각 자극에 대한 단순주의력 검사 결과에서 두 집단 간 '정 상'과 '저하'에 대한 빈도를 비교분석을 했을 때 통계적으로 유 의한 차이를 보이지 않았다.

\section{고 찰}

본 연구는 $\mathrm{ASD}$ 아동청소년에서 보일 수 있는 심각한 어려움 인 공격적 문제행동의 특징에 대해서 알아보기 위해서 공격 적 문제행동 보이는 $\mathrm{ASD}$ 아동과 그렇지 않은 $\mathrm{ASD}$ 아동 사이 의 임상양상과 주의력 검사 결과를 비교 분석하였다. 그 결과 공격적인 문제행동을 보이는 집단에서 자해행동이 좀 더 많 은 경향을 보였으며 $\mathrm{K}-\mathrm{CBCL}$ 에서는 외현화문제, 사회적 미성 숙문제, 비행문제, 공격적문제의 T점수가 통계적으로 유의하 게 높았고, 이외에도 불안/우울과 사고문제, 주의집중문제의 T점수가 또한 높은 양상을 보였다. 반면에 지능과 사회적 의사 소통이나 신경심리 검사를 이용한 주의력 평가에서는 유의한 차이를 관찰할 수 없었다.

이 연구결과는 과거의 연구와 비교하였을 때 지능이나 의사 소통이 공격적인 문제행동과 관련이 없다는 일부 연구 ${ }^{5,8,9}$ 와 일치하는 결과이다. 공격적인 행동의 여부와 직접 관련이 있는 
외현화문제, 비행문제, 공격적문제와 달리 불안과 우울, 사고 문제, 그리고 주의집중문제가 공격성을 보이는 $\mathrm{ASD}$ 아동에서 높게 나타난 것은 주목할 만하다. 불안과 우울 같은 공존 병 리가 $\mathrm{ASD}$ 의 행동문제와 밀접한 관련이 있다는 이전 연구들은 대부분-미취학 아동이나 어린이를 대상으로 실시한 연구 ${ }^{25-27)}$ 들로 심각한 공격적인 문제행동을 보일 수 있는 청소년기를
대상으로 한 연구는 부족하다. 분노와 관련된 반복적인 생각 이 우울증상, 공격성 등과 관련이 있다는 연구 ${ }^{28)}$ 가 있으나 공 격적인 행동과 우울증과의 직접적인 관련성을 평가하지는 않 았다.

주의집중의 문제는 좀 더 연구가 필요하겠지만 $\mathrm{ASD}$ 에서 높 은 공존율을 보이는 $\mathrm{ADHD}$ 와 관련성이 있을 것으로 보인다.

Table 2. Result of clinical rating scale of participants

\begin{tabular}{|c|c|c|c|}
\hline & $\begin{array}{c}\text { ASD w/ aggressive } \\
\text { behavior }(n=9)\end{array}$ & $\begin{array}{c}\text { ASD w/o aggressive } \\
\text { behavior }(n=7)\end{array}$ & p-value* \\
\hline \multicolumn{4}{|c|}{ Behavior Problem Inventory $(\text { mean } \pm S D)^{\dagger}$} \\
\hline Self-injurious (S) & $5.1 \pm 5.24$ & $1.1 \pm 1.46$ & 0.097 \\
\hline Self-injurious ( $F$ ) & $6.4 \pm 5.31$ & $1.2 \pm 1.70$ & 0.073 \\
\hline Stereotype (S) & $15.2 \pm 12.76$ & $9.4 \pm 12.56$ & 0.535 \\
\hline Stereotype (F) & $17.8 \pm 12.46$ & $10.8 \pm 14.13$ & 0.209 \\
\hline Aggressive/destructive (S) & $5.1 \pm 7.71$ & 0 & 0.004 \\
\hline Aggressive/destructive (F) & $4.4 \pm 4.75$ & 0 & 0.004 \\
\hline Total (S) & $25.5 \pm 21.85$ & $9.8 \pm 13.35$ & 0.097 \\
\hline Total (F) & $28.7 \pm 15.80$ & $12.7 \pm 14.97$ & 0.038 \\
\hline \multicolumn{4}{|c|}{ Korean-Child Behavior CheckList (mean \pm SD) } \\
\hline Total problems & $77.6 \pm 10.31$ & $63.0 \pm 12.20$ & 0.016 \\
\hline Internalizing problems & $70.3 \pm 11.61$ & $60.5 \pm 15.36$ & 0.114 \\
\hline Externalizing problems & $73.3 \pm 11.26$ & $55.2 \pm 6.62$ & 0.001 \\
\hline Anxious/depressed & $68.7 \pm 7.83$ & $60.1 \pm 10.76$ & 0.071 \\
\hline Withdrawn & $67.3 \pm 9.05$ & $60.7 \pm 6.15$ & 0.114 \\
\hline Somatic complaints & $61.7 \pm 10.04$ & $57.8 \pm 11.49$ & 0.174 \\
\hline Social problems & $73.8 \pm 7.65$ & $64.0 \pm 5.41$ & 0.003 \\
\hline Thought problems & $71.1 \pm 6.50$ & $60.7 \pm 10.33$ & 0.055 \\
\hline Attention problems & $76.3 \pm 10.03$ & $66.0 \pm 4.28$ & 0.055 \\
\hline Delinquent problems & $66.2 \pm 6.81$ & $55.2 \pm 5.61$ & 0.005 \\
\hline Aggressive problems & $71.4 \pm 8.73$ & $56.2 \pm 6.44$ & 0.003 \\
\hline \multicolumn{4}{|c|}{ Social Communication Questionnaire (mean \pm SD) } \\
\hline Social interaction (L) & $9.6 \pm 2.23$ & $7.5 \pm 3.82$ & 0.252 \\
\hline Communication (L) & $7.2 \pm 1.64$ & $6.4 \pm 2.99$ & 0.758 \\
\hline Stereotype (L) & $5.5 \pm 2.06$ & $4.1 \pm 2.26$ & 0.210 \\
\hline Total score (L) & $23.2 \pm 3.86$ & $19.4 \pm 9.89$ & 0.408 \\
\hline Social interaction (C) & $6.7 \pm 2.43$ & $5.1 \pm 2.73$ & 0.299 \\
\hline Communication (C) & $6.0 \pm 2.00$ & $4.7 \pm 1.60$ & 0.142 \\
\hline Stereotype (C) & $4.5 \pm 2.00$ & $3.8 \pm 3.13$ & 0.681 \\
\hline Total score (C) & $18.6 \pm 7.48$ & $13.8 \pm 6.96$ & 0.174 \\
\hline
\end{tabular}

*Mann-Whitney U-test, ${ }^{\dagger}$ there were seven participants in group of ASD w/ aggressive behavior in Behavior Problem Inventory section. ASD: autism spectrum disorder, C: current, F: frequency, L: lifetime, n: number, S: severity, SD: standard deviation

Table 3. Result of attention test of participants

\begin{tabular}{lccc}
\hline \multicolumn{1}{c}{ CAT-visual stimuli (normal $n, \%)$} & ASD w/ aggressive behavior $(n=7)$ & ASD w/o aggressive behavior $(n=7)$ & $p$-value* \\
\hline Omission error & $2(28.6 \%)$ & $2(28.6 \%)$ & 1.000 \\
Commission error & $6(85.7 \%)$ & $5(71.4 \%)$ & 1.000 \\
Mean response time & $3(42.9 \%)$ & $5(71.4 \%)$ & 0.592 \\
Response time standard deviation & $4(57.1 \%)$ & $3(42.9 \%)$ & 1.000 \\
\hline
\end{tabular}

*Fisher exact test, two-tailed. ASD: autism spectrum disorder, CAT: Comprehensive Attention Test, n: number 
약 $28 \%$ 의 공존율이 보고된 연구하가 있을 뿐만 아니라 최근 의 연구에서는 $\mathrm{ASD}$ 아동에서 보이는 공격성에 대한 조절 가 능한 요인으로 주의력결핍 문제를 제시한 연구 ${ }^{29}$ 가 있다. 이처 럼 공격성을 보이는 $\mathrm{ASD}$ 아동이 주의집중력의 어려움을 보일 가능성이 있으나, 본 연구에서 이를 확인하기 위해 시행한 주의 집중력 검사에서는 두 집단 간의 차이를 보이지 않았다. 앞서 $\mathrm{ASD}$ 아동에서 보이는 주의집중력에 대한 Chen 등 29) 연구에서 도 신경심리검사도구가 아닌 설문평가도구를 이용하여 $\mathrm{ADHD}$ 증상을 평가하였다. 이는 $\mathrm{ASD}$ 아동을 비롯하여 의사소통이 어렵거나 지능이 낮은 아동들을 대상으로, 지시에 따라서 능 동적으로 수행해야 하는 일반적인 신경심리검사로는 주의력 평가를 제대로 하기 어려울 수 있음을 보여준다. 아동에서 주 의력의 저하로 보일 수 있는 우울이나 불안과 같은 정서문제, 정신병적 증상, 환경변화 등이 아닌 $\mathrm{ADHD}$ 와 관련 있는 주의 력의 저하나 충동성 등이 $\mathrm{ASD}$ 아동에서 보이는 공격성을 설 명할 수 있는지는 추가적인 연구가 필요하다. 공격적인 문제 행동을 보일 수 있는 정신병리에 대한 상세한 감별과 이해가 가 능하다면 이에 따른 약물치료와 비약물적 치료를 좀 더 다양 하게 선택할 수 있는 근거가 될 수 있을 것이다.

본 연구에서는 공격적 문제행동의 존재를 부모의 기술과 임상에서 시행한 관찰을 종합하여 결정하였다. 본 연구에 참 여한 아동들을 대상으로 $\mathrm{K}-\mathrm{CBCL}$ 의 점수를 측정한 결과를 보면 T점수가 59 87점 사이였고, 평균은 71.4(SD 8.73)였다. 이 는 일반적으로 임상적 의미가 있는 T점수인 70점 기준이나, 400여 명 아동을 대상으로 한 연구 ${ }^{8}$ 에서 공격적인 행동의 존 재 여부를 $\mathrm{K}-\mathrm{CBCL}$ 의 공격적 문제행동 T점수 70점 이상으 로 정의한 것과 비교하였을 때 차이를 보인다. 이는 두 연구 모두 약물치료여부를 통제하지 않고 평가를 시행한 것을 고 려하더라도 $\mathrm{ASD}$ 아동을 대상으로 공격적인 문제행동 평가 시 설문 평가도구만을 이용한 평가로는 $\mathrm{ASD}$ 아동에서 치료적 개 입이 필요한 공격적 문제행동을 충분히 보여주지 못할 가능성 을 보여준다.

또한 문제행동척도(BPI)를 이용한 평가에서 자해행동이 공 격적인 행동을 보이는 $\mathrm{ASD}$ 아동에서 좀 더 많은 것으로 나타 났다. 발달장애아동의 공격성에 대한 연구에서 많은 경우 자해 행동(self-injurious behavior)을 공격적인 문제행동에 포함하 였다. 연구에 따라서는 이를 세분화하려는 시도를 하여 Carroll 등이 의 연구에서는 타인에 대한 정서적인 공격성과 의도적인 공격성, 자해행동 등으로 나누어 평가하였다. 이 연구에서는 이 들 공격성의 형태에 따른 임상양상이 다소 차이를 보여 지능 이 70 이하인 경우에서 자해행동과 공격성이 높았고, 자해행동 을 보이는 집단에서 이자극성이 가장 높은 결과를 보였다. 다 만 이들 다양한 공격성을 보이는 집단들을 대상으로 리스페
리돈 약물 치료를 시행하였는데, 그 치료 반응은 집단 간 차 이를 보이지 않았다.

본 연구에서 $\mathrm{ASD}$ 아동의 공격적인 문제행동이 사회적 미성 숙, 비행문제 등과 관련이 있고, 또한 불안과 우울, 사고문제, 주의집중의 문제와 관련되어 있음이 시사되었다. 또한 자해행 동이 공격적인 행동을 보이는 경우에 더 나타났다. 그러나 다 음과 같은 몇 가지 주요 제한점이 있어 이는 향후의 연구에서 고려되어야 할 것으로 보인다. 첫째로 연구에 참여한 대상아 동의 수가 적다. 이로 인해 통계적으로 경향성을 보인 연구분 석도 의미 있는 결과로 고려하였다. 이는 연구 참여기관을 다 양화하고 향후에 평가시간과 노력을 최소화할 수 있는 도구 를 이용한 연구를 통해서 연구대상자의 확대가 가능할 것으 로 보인다. 두 번째로 이들 참여자들의 약물치료나 행동치료 와 같은 치료적 개입에 대한 평가가 부족하였다. 이러한 치료 적 개입이 공격적인 행동문제의 임상양상에 영향이 있을 것 으로 보이는데 이러한 고려가 충분하지 않았다. 다만 약물치 료와 병원입원력 등을 조사하여 공격적인 행동문제를 보이는 아동 중 9명(90\%)이 약물치료를 요하였으며, 50\%인 5명은 이 로 인해 입원치료를 했던 과거력이 있었다. 따라서 이와 같이 심각한 공격적인 행동을 보이는 아동을 모집하여 공격적인 문제가 없는 아동과 차별성을 보이는 집단을 모집하였다. 마지 막으로 환경의 변화 등에 대한 평가가 부족하였다. 인구학적 변수와 정신병리만이 아닌 생활의 변화나 스트레스, 수면과 식이의 변화와 같은 변수를 포함하고 더 나아가 유전요인, 뇌 영상, 뇌파 검사 등과 같은 포괄적인 평가를 아우르는 연구를 통해서 $\mathrm{ASD}$ 아동에서 보이는 공격적인 행동에 대한 이해를 높일 수 있을 것으로 기대한다.

\section{결 론}

본 연구는 $\mathrm{ASD}$ 아동에서 공격적인 문제행동의 임상적 특 징을 알아보고 이를 통한 좀 더 깊은 이해를 통해 치료에 대 한 근거기반을 마련하고자 시행되었다. 그 결과 공격적인 문 제행동을 보이는 $\mathrm{ASD}$ 아동에서 불안과 우울과 같은 정서적 인 어려움, 주의집중력의 문제 등이 좀 더 많을 수 있음이 시사 되었고, 자해행동이 동반할 가능성이 높은 것으로 나타났다. 이는 공격적인 문제행동을 보이는 $\mathrm{ASD}$ 아동이 이러한 정신 병리를 동반하고 있을 가능성을 제시한다. 더 나아가 공격적인 문제행동 평가와 치료개입 시에 이에 대한 고려를 한다면 좀 더 다양한 평가 및 치료선택이 가능할 것으로 보인다.

중심 단어:공격적 문제행동; 자폐스펙트럼장애; 주의집중. 


\section{Acknowledgments}

본 연구는 국립정신건강센터 연구비 지원으로 이루어졌음.

\section{Conflicts of Interest}

The authors have no financial conflicts of interest.

\section{REFERENCES}

1) American Psychiatric Association. Diagnostic and Statistical Manual of Mental Disorders: DSM-5. 5th ed. Arlington, VA: American Psychiatric Association;2013

2) Matson JL, Nebel-Schwalm MS. Comorbid psychopathology with autism spectrum disorder in children: an overview. Res Dev Disabil 2007;28:341-352.

3) Simonoff E, Pickles A, Charman T, Chandler S, Loucas T, Baird G. Psychiatric disorders in children with autism spectrum disorders: prevalence, comorbidity, and associated factors in a populationderived sample. J Am Acad Child Adolesc Psychiatry 2008;47:921929.

4) Farmer C, Butter E, Mazurek MO, Cowan C, Lainhart J, Cook EH, et al. Aggression in children with autism spectrum disorders and a clinic-referred comparison group. Autism 2015;19:281-291.

5) Kanne SM, Mazurek MO. Aggression in children and adolescents with ASD: prevalence and risk factors. J Autism Dev Disord 2011; 41:926-937.

6) Dominick KC, Davis NO, Lainhart J, Tager-Flusberg H, Folstein S. Atypical behaviors in children with autism and children with a history of language impairment. Res Dev Disabil 2007;28:145-162.

7) Estes AM, Dawson G, Sterling L, Munson J. Level of intellectual functioning predicts patterns of associated symptoms in school-age children with autism spectrum disorder. Am J Ment Retard 2007; 112:439-449.

8) Hill AP, Zuckerman KE, Hagen AD, Kriz DJ, Duvall SW, van Santen J, et al. Aggressive Behavior Problems in Children with Autism Spectrum Disorders: prevalence and correlates in a large clinical sample. Res Autism Spectr Disord 2014;8:1121-1133.

9) De Giacomo A, Craig F, Terenzio V, Coppola A, Campa MG, Passeri G. Aggressive behaviors and verbal communication skills in autism spectrum disorders. Glob Pediatr Health. 2016;3:2333794X16644360.

10) Matson JL, Cervantes PE. Assessing aggression in persons with autism spectrum disorders: an overview. Res Dev Disabil 2014;35: 3269-3275.

11) Bronsard G, Botbol M, Tordjman S. Aggression in low functioning children and adolescents with autistic disorder. PLoS One 2010;5: e14358.

12) Mulligan CK, Trauner DA. Incidence and behavioral correlates of epileptiform abnormalities in autism spectrum disorders. J Autism Dev Disord 2014;44:452-458.

13) Burrows EL, Laskaris L, Koyama L, Churilov L, Bornstein JC, HillYardin EL, et al. A neuroligin-3 mutation implicated in autism causes abnormal aggression and increases repetitive behavior in mice. Mol Autism 2015;6:62.

14) Sala M, Braida D, Lentini D, Busnelli M, Bulgheroni E, Capurro V, et al. Pharmacologic rescue of impaired cognitive flexibility, social deficits, increased aggression, and seizure susceptibility in oxytocin receptor null mice: a neurobehavioral model of autism. Biol Psychiatry 2011;69:875-882.

15) Shea S, Turgay A, Carroll A, Schulz M, Orlik H, Smith I, et al. Risperidone in the treatment of disruptive behavioral symptoms in children with autistic and other pervasive developmental disorders.
Pediatrics 2004;114:e634-641.

16) Parikh MS, Kolevzon A, Hollander E. Psychopharmacology of aggression in children and adolescents with autism: a critical review of efficacy and tolerability. J Child Adolesc Psychopharmacol 2008; 18:157-178.

17) McDougle CJ, Stigler KA, Erickson CA, Posey DJ. Atypical antipsychotics in children and adolescents with autistic and other pervasive developmental disorders. J Clin Psychiatry 2008;69 Suppl 4: 15-20.

18) Fitzpatrick SE, Srivorakiat L, Wink LK, Pedapati EV, Erickson CA. Aggression in autism spectrum disorder: presentation and treatment options. Neuropsychiatr Dis Treat 2016;12:1525-1538.

19) Rojahn J, Matson JL, Lott D, Esbensen AJ, Smalls Y. The Behavior Problems Inventory: an instrument for the assessment of self-injury, stereotyped behavior, and aggression/destruction in individuals with developmental disabilities. J Autism Dev Disord 2001;31: 577-588.

20) Bang SY, Lee JW, Hwang SH, Hong EJ, Park JH. Development of tools and protocols assessing problematic behaviors in children with developmental disorders. Seoul: National Center for Mental Health;2013.

21) Achenbach TM. Manual for the child: behavior checklist and revised child behavior profile. Burlington, VT: University Vermont, Dept. Psychiatry; 1983.

22) Berument SK, Rutter M, Lord C, Pickles A, Bailey A. Autism screening questionnaire: diagnostic validity. Br J Psychiatry 1999;175: 444-451.

23) Kim JH, Sunwoo HJ, Park SB, Noh DH, Jung YK, Cho IH, et al. A validation study of the Korean version of Social Communication Questionnaire. J Korean Acad Child Adolesc Psychiatry 2015;26: 197-208.

24) Yoo HK, Lee J, Kang SH, Park EH, Jung J, Kim BN, et al. Standardization of the Comprehensive Attention Test for the Korean children and adolescents. J Korean Acad Child Adolesc Psychiatry 2009; 20:68-75.

25) Matson JL, Mahan S, Fodstad JC, Worley JA, Neal D, Sipes M. Effects of symptoms of co-morbid psychopathology on challenging behaviours among infants and toddlers with autistic disorder and PDD-NOS as assessed with the Baby and Infant Screen for Children with aUtIsm Traits (BISCUIT). Dev Neurorehabil 2011;14:129-139.

26) Cervantes P, Matson JL, Tureck K, Adams HL. The relationship of comorbid anxiety symptom severity and challenging behaviors in infants and toddlers with autism spectrum disorder. Res Autism Spectr Disord 2013;7:1528-1534.

27) Niditch LA, Varela RE, Kamps JL, Hill T. Exploring the association between cognitive functioning and anxiety in children with autism spectrum disorders: the role of social understanding and aggression. J Clin Child Adolesc Psychol 2012;41:127-137.

28) Patel S, Day TN, Jones N, Mazefsky CA. Association between anger rumination and autism symptom severity, depression symptoms, aggression, and general dysregulation in adolescents with autism spectrum disorder. Autism 2017;21:181-189.

29) Chen C, Shen YD, Xun GL, Cai WX, Shi LJ, Xiao L, et al. Aggressive behaviors and treatable risk factors of preschool children with autism spectrum disorder. Autism Res 2017;10:1155-1162.

30) Carroll D, Hallett V, McDougle CJ, Aman MG, McCracken JT, Tierney E, et al. Examination of aggression and self-injury in children with autism spectrum disorders and serious behavioral problems. Child Adolesc Psychiatr Clin N Am 2014;23:57-72. 